\title{
Comparative proteomics analysis provide novel insight into laminitis in Chinese Holstein cows
}

\author{
Shu-Wei Dong ${ }^{1,2}$, Shi-Dong Zhang ${ }^{1}$, Dong-Sheng Wang ${ }^{1}$, Hui Wang ${ }^{1}$, Xiao-Fei Shang ${ }^{1}$, Ping Yan², \\ Zuo-Ting Yan ${ }^{1 *}$ and Zhi-Qiang Yang ${ }^{1 *}$
}

\begin{abstract}
Background: Laminitis is considered as the most important cause of hoof lameness in dairy cows, which causes abundant economic losses in husbandry. Through intense efforts in past decades, the etiology of laminitis is preliminarily considered to be subacute ruminal acidosis; however, the pathogenesis of laminitis needs further research. The differentially expressed proteins (DEP) were detected in plasma of healthy cows and clinical laminitis cows by two-dimensional gel electrophoresis (2-DE) and identified by matrix-assisted laser desorption/ionization time-of-flight mass spectrometry.

Results: Nineteen protein spots were differentially expressed, and 16 kinds of proteins were identified after peptide mass fingerprint search and bioinformatics analysis. Of these, 12 proteins were differentially up-regulated and 4 down-regulated. Overall, these differential proteins were involved in carbohydrate metabolism, lipids metabolism, molecular transport, immune regulation, inflammatory response, oxidative stress and so on.

Conclusions: The DEPs were closely related to the occurrence and development of laminitis and the lipid metabolic disturbance may be a new pathway to cause laminitis in dairy cows. The results provide the theory foundation for further revealing the mechanism of laminitis and screening the early diagnostic proteins and therapeutic target.
\end{abstract}

Keywords: Comparative proteomics, 2-DE, Laminitis, Plasma, Dairy cow

\section{Background}

With China's steady and high-speed economic development, the import amount of dairy cow, frozen sperm, and embryo are strongly increasing for meeting the dairy industry demands. At the same time, infectious diseases have been effectively controlled, but the animal welfare and some nutrition metabolic diseases are easy to be ignored. Lameness is an increasing disease in dairy cows that are associated with higher production, more intensive feeding, and confined conditions. It has been considered as the third serious disease, following mastitis and reproductive diseases in dairy cows in China. The problem's prevalence is a significant contributor to

\footnotetext{
* Correspondence: yanping@caas.cn; yanzuoting@caas.cn

${ }^{1}$ Key Laboratory of Veterinary Pharmaceutical Development of Ministry of Agriculture/ Engineering \& Technology Research Center of Traditional Chinese Veterinary Medicine of Gansu Province/Lanzhou Institute of Husbandry and Pharmaceutical Sciences of Chinese Academy of Agricultural Sciences, Lanzhou 730050, People's Republic of China

Full list of author information is available at the end of the article
}

compromised animal welfare and the economic loss in the dairy industry.

Laminitis-an inflammation of the laminar corium in the hoof wall-is a common underlying cause of lameness, accounting for $41 \%$ of the cases of lameness identified in cows [1]. It can result in many kinds of claw horn lesions including sole hemorrhages, white line disease, and sole ulcers in dairy cattle [2], which highly affect a cow's welfare, production, and longevity. Laminitis is divided into two stages depending on clinical presentation: subclinical and clinical stages. The subclinical phase usually does not have any obvious evident syndrome, so the sick cattle is always ignored and misses the best opportunity of the treatment. Thus, laminitis has been an invisible killer of dairy cows. In recent years, many scholars have studied the etiology of laminitis [3-5], laminar morphology [6], metabolism [7], pathophysiology [1], clinical diagnosis [8,9], and comprehensive treatment [10] in laminitis cows. Through intense efforts to understand the root cause of clinical 
laminitis in past decades, the etiology of laminitis is preliminarily considered to be subacute ruminal acidosis (SARA) [11, 12], but the pathogenesis of laminitis is not clearly understood. Laminitis that was been proved refractory to conventional research approaches has been especially frustrating for clinicians because of the dearth of new treatment strategies for age-old diseases [13].

Proteins are the final executants of biological functions in life. Tiny alterations of protein expression happen in all physiological and pathological processes. Thousands of proteins are secreted in plasma by cells or tissues that contain rich information concerning overall pathophysiology of the patient or diseased animal [14]. Therefore, the analysis of the profile of plasma protein alterations is a promising way to find the potential biomarker and shed light on the pathogenesis of disease. At present, comparative proteomics have identified a large number of differentially expressed proteins associated with diseases. Although roles and mechanisms of such proteins in the pathogenesis need to be further proved, at least some of them may be potential biomarkers for early diagnosing diseases. So, the technology based on proteomics has a wide prospect in clinical diagnosis and prevention of diseases.

However, the proteomics application in animal science and veterinary is still in its infancy, and studies have mainly been directed toward production traits [15] and epidemic diseases [16, 17]. Proteomics also provides a novel approach to investigate the pathogenesis of laminitis [18]. Hannah analyzed the proteomics of lamellar tissue of equine laminitis and discovered that keratins could serve as serum biomarkers for the developmental phase of endocrinopathic laminitis [19]. So far, only two proteomic studies on claw tissues in dairy cattle have been published [20,21], and very little information are available on the presence of specific proteins in plasma. Laminitis is a local manifestation of systemic metabolism disorder in cows; therefore, some corresponding changes may occur in plasma proteome [22].To investigate this broad hypothesis, two-dimensional gel electrophoresis (2-DE) coupled with matrix-assisted laser desorption/ionization time-of-flight mass spectrometry (MALDI-TOF MS) was used to detect differentially expressed proteins in plasma, as a first step toward characterizing global alterations in dairy cows with clinical laminitis. The objective of our study was to screen the potential protein biomarkers that monitor the occurrence and the drug target of laminitis and shed light on pathogenesis with the intent of developing novel preventive strategies and therapeutic approaches. The current study provides a novel report of comparing proteomics analysis of plasma in dairy cows with laminitis.

\section{Methods}

\section{Ethics statement}

The experiment was conducted in accordance with the good animal practices requirements of the Animal Ethics Procedures and Guidelines of the People's Republic of China. This study was approved by the Institutional Animal Care and Use Committee of Lanzhou Institute of Husbandry and Pharmaceutical Sciences of CAAS (Approval No. LIHPSACUC2011-012).

\section{Case definition of laminitis}

A total of 4680 Holstein cows were selected from May to August in 2011in the Reproduction and Breeding Demonstration Center of Chinese Holstein Dairy Cow of Gansu Province, which was the member of the Chinese National technological system of dairy industry. Laminitis was identified with at least one of the following claw horn lesions: double sole, solar ulcer, solar hemorrhage, white line disease, and solar abscess [23]. A case of cow usually has the following clinical signs: redness, heat, pain, or sensitivity to percussion, and swelling of the lamellar hoof, as well as the corresponding systemic symptoms, which are diagnosed by hoof trimmers and veterinarians. A total of 36 adult cows in lactation with acute laminitis were selected as a sick group from the dairy herds during the routine herd trimming, with at least one hoof suffering from laminitis. A total of 15 healthy dairy cows with no evident clinical signs of other diseases were included as a control group. All of the cows enrolled in the study aged 3-5 years, were around $400 \mathrm{~kg}$ in body weight, and had not received any drug treatment for 1 month before trials. All procedures were followed up by a veterinary assistance and according to the corresponding ethical and animal welfare guidelines.

\section{Collection and selection of blood samples}

Blood samples were withdrawn from the jugular vein by cava venepuncture using a 16-gauge needle in $10 \mathrm{~mL}$ tubes and immediately transferred into sealed vacutainer glass tubes that contained EDTA-K2 as an anticoagulant (for plasma). After collection, samples were placed on ice and transferred to the laboratory in $4 \mathrm{~h}$. Plasma was obtained by centrifugation at $2000 \mathrm{~g}$ for $15 \mathrm{~min}$ at $4{ }^{\circ} \mathrm{C}$. To emphasize proteomic differences between the groups while eliminating potential individual contributions, six cows were randomly selected from the same group and equal volumes of plasma were pooled from them. Two mixed plasma samples were available for the next proteomic experiment, which included comparison between sick and healthy groups. 


\section{Preparation of protein samples and depletion of abundant proteins}

Plasma samples were analyzed using two commercial kits: Albumin and IgG Removal kit (GE Healthcare, NJ USA) and 2-D Clean Up kit (GE Healthcare, NJ USA). The most abundant proteins of albumin and immunoglobulin (IgG) in plasma were removed by the immune affinity-based method according to the manufacturer's instructions. After fractionation, samples were desalted using the 2-D Clean Up kit.

The protein precipitate in samples were resuspended in a lysis buffer containing $8 \mathrm{M}$ urea, 2 \% 3-[(3-cholamidopropyl) dimethylammonio]-1-propanesulfonate (CHAPS) (w/v), $18 \mathrm{mM}$ dithiothreitol (DTT), $1 \%$ ampholytes (v/v), and bromophenol blue (silver-stained gels) or $30 \mathrm{mM}$ Tris- $\mathrm{HCl}$, and sonicated to completely dissolve the aggregated protein ( $15 \mathrm{~s}, 0.5$ cycles/s, $60 \%$ amplitude). Samples were centrifuged at $16,000 \mathrm{~g}$ for $15 \mathrm{~min}$ at $4{ }^{\circ} \mathrm{C}$ in a $5415 \mathrm{R}$ centrifugal machine (Eppendorf 5415R, Germany) to get suspensions, which were diluted in the lysis buffer using protease inhibitor (Complete EDTA-free Protease Inhibitor Cocktail Tablets, Roche, Spain) until the final protein concentration was $5-10 \mu \mathrm{g} / \mu \mathrm{L}$ as determined using the 2-D QUANT KIT (GE Healthcare, NJ, USA). Samples were aliquoted once the experiment was over and stored at $-80{ }^{\circ} \mathrm{C}$ until 2-DE analysis.

\section{2-DE procedure}

To discover the potential new biomarkers in plasma, 2DE was performed to screen differentially expressed proteins between healthy and sick cows. Isoelectric focusing (IEF) was run on an Ettan IPG phor II (GE Healthcare, CA, USA) using $24 \mathrm{~cm}$ nonlinear immobilized $\mathrm{pH}$ gradient strips ( $\mathrm{pH}$ 3-10; GE Healthcare). Protein samples $(150 \mu \mathrm{g})$ pooled with rehydration solution (8 M urea, 2 \% CHAPS, $20 \mathrm{mM}$ DTT, $0.5 \%$ (v/v) immobilized $\mathrm{pH}$ gradient (IPG) buffer ( $\mathrm{pH} 3-10)$, and $0.001 \%$ bromophenol blue) were placed for $12 \mathrm{~h}$ at $4{ }^{\circ} \mathrm{C}$. The linear ramping mode of the IEF voltage was applied in the focusing program as description in reference [24]. Strips were sequentially incubated for $15 \mathrm{~min}$ in $10 \mathrm{~mL}$ equilibration solution with $2.5 \%(\mathrm{w} / \mathrm{v}) \mathrm{DTT}$ or iodoacetamide (IAA). Second-dimension electrophoresis was performed on $12.5 \%$ sodium dodecyl sulfate gels in an Ettan DALT six apparatus (Amersham Bioscience, Uppsala, Sweden) with constant power at $5 \mathrm{~W}$ per gel for the first $30 \mathrm{~min}$, and then at $12 \mathrm{~W}$ per gel for 6-7 h until the bromophenol blue line reached the bottom of the gels. Gels were treated in triplicate and silver stained according to published procedures [25]. Gels were scanned at 300 dpi resolution (UMAX USB2100XL, Taiwan, China), and the profiles were renamed as the experiment.

\section{Image analysis and protein identification}

Differential analysis was performed using Image Master 2D platinum software (Version 5.0, GE Healthcare, CA, USA) for spot detection, quantification, matching, and comparative and statistical analyses. Data were averaged from three independent gels, and the mean and standard deviations were calculated and assessed for statistical significance by normalized intensities of spots. Finally the differentially expressed proteins were defined between the sick and healthy groups with a paired $t$ test if $P$ values were less than 0.05 , and the average spot intensity was greater than threefold.

Protein spots of interest were excised manually from the gel, subjected to destaining and trypsin digestion according to the protocol described by $\mathrm{Wu}$ [24], and purified using ZipTip microliter plates (Millipore). MALDI-TOF MS analysis of tryptic peptides was performed on an Ultraflex TOF/TOF instrument (Bruker Daltonics). Proteins were identified by peptide mass fingerprint (PMF) using the Mascot search engine (http://www.matrixscience.com; Matrix Science Ltd., London, UK) and the Swiss-Prot 55.4 database.

\section{Bioinformatics analysis}

The identified proteins were searched in the Uniprot database (http://www.uniprot.org/), AgBase (http://ww w.agbase.msstate.edu/), and published literature for their functions [26]. According to the combined search results, these proteins were divided into different functional groups. Categorical annotation was supplied in the form of gene ontology (GO) biological process (BP), molecular function (MF), cellular component (CC), as well as participation in a Kyoto Encyclopedia of Genes and Genomes (KEGG)pathway and membership in a protein complex as defined by the comprehensive resource of mammalian protein complexes (CORUM) [27].

\section{Validation of differentially expressed protein}

To add confidence to the results obtained by 2-DE, 2 of 16 differentially expressed proteins in plasma were measured in healthy and sick groups. The concentrations of haptoglobin were detected by Bovine ELISA kits (Shanghai Institute of Biological enzyme-linked, Shanghai, China). ApoA-I in plasma was detected by immunoturbidimetric method in the automatic biochemical analyzer (Mindary 420, Shenzhen, China) using commercial test kits for human (Mindary, Shenzhen, China). The standard curve was developed with the known ApoA-I concentration $(0 \mathrm{~g} / \mathrm{L}, 0.180 \mathrm{~g} / \mathrm{L}$, $0.530 \mathrm{~g} / \mathrm{L}, 1.26 \mathrm{~g} / \mathrm{L}$, and $2.45 \mathrm{~g} / \mathrm{L})$. The procedure was performed according to the manufacturer's instructions.

Plasma samples (1:2000 dilutions) were added in duplicate to each well in enzyme-linked immunosorbent 
assay (ELISA) plate precoated with monoclonal antibody (McAb) against bovine haptoglobin, and then $10 \mu \mathrm{L}$ of biotin-labeled McAb and $50 \mu \mathrm{L}$ of streptavidin-HRP conjugates were added to the wells. After incubation at $37{ }^{\circ} \mathrm{C}$ for $1 \mathrm{~h}$, the ELISA plate was washed for three times using PBST [0.5 \% (v/v) Tween-20, PBS, pH 7.4]. Coloration was developed by 3', 5, 5' -tetramethylbenzidine solution, and the reaction was stopped with $50 \mu \mathrm{L}$ of $2 \mathrm{M} \mathrm{H}_{2} \mathrm{SO}_{4}$. The absorbance was measured at a wavelength of $450 \mathrm{~nm}$. In ELISA test, bovine haptoglobin solutions with known concentrations $(800 \mathrm{mg} / \mathrm{L}, 400 \mathrm{mg} /$ $\mathrm{L}, 200 \mathrm{mg} / \mathrm{L}, 100 \mathrm{mg} / \mathrm{L}$, and $50 \mathrm{mg} / \mathrm{L}$ ) were used to prepare a standard curve according to the ELISA procedure described by the manufacture. Haptoglobin concentration in plasma was calculated according to the sample absorbance and standard curve.

\section{Assay of antioxidant ability of plasma in dairy cows}

Plasma samples were analyzed for the total antioxidative capacity (T-AOC), malonaldehyde (MDA), super oxygen dehydrogenases (SOD), and glutathione peroxidase (GSH-Px) using colorimetric assay kits (Nanjing Jiancheng Bioengineering Institute, Jiangsu, China), and detected by microplate reader (Spectra Max M2, Molecular Devices, CA, USA). All samples were tested in duplicate. The T-AOC concentration was determined by the reaction of phenanthroline and $\mathrm{Fe}^{2+}$ using spectrophotometer at $520 \mathrm{~nm}$. MDA was measured by the thiobarbituric acid method. SOD activity was determined by inhibiting nitroblue tetrazolium reduction due to superoxide anion generation by a xanthinexanthine oxidase system. The GSH-Px level was determined using the direct measurement of the remaining GSH after the enzyme-catalyzed reaction. All assay procedures were performed according to the manufacturer's instructions.

\section{Statistical analysis}

Statistical analysis was performed using the SPSS statistical package $v$ 17.0. Normality of data was tested using the one-sample Kolmogorov-Smirnov test. Data were analyzed by one-way analysis of variance, and differences between group means were evaluated with the Duncan test. Differences between groups were analyzed with independent $t$ test $(P<0.05)$.

\section{Results}

\section{Comparative proteomic analysis of plasma samples}

Scanning of 2-DE gel maps showed that several spots did not correspond to proteins, which may be due to contamination or gel impurities. Therefore, these spots were eliminated in comparative analysis. Plasma proteomic profiles of healthy and sick groups were analyzed by Image Master. Representative 2-DE profiles of healthy and sick groups are illustrated in Fig. 1a and b. Qualitative analysis revealed approximately 763 and 757 protein spots on each 2-DE images. While the quantitative analysis of the spots' expression showed that a total of 19 stained protein spots (Fig. 1) showed significant changes of at least threefold up- or down-regulated expression in the healthy group (Fig. 2). Among them, 15 spots (M-01 to M-15) were up-regulated while other 4 spots (M-16 to M-19) were down-regulated in response to the occurrence of laminitis.

\section{Protein identification by MS}

All differentially expressed protein spots were excised from the 2-DE gels and subjected to trypsin digestion. The peptide mixtures were submitted to MALDI-TOF MSfor identification. Peptide mass fingerprinting was searched by Mascot in NCBInr database (Version 20101030) with other mammalian as taxonomy. Nineteen of them were positively identified as 16 kinds of proteins (Table 1). Spot889, spot1468, and spot1477

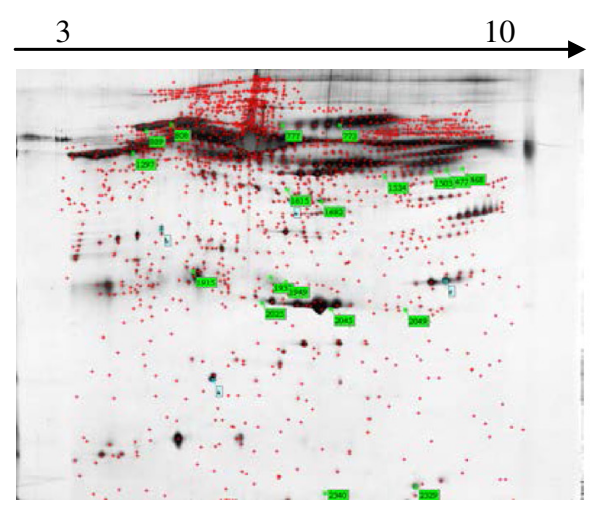

A

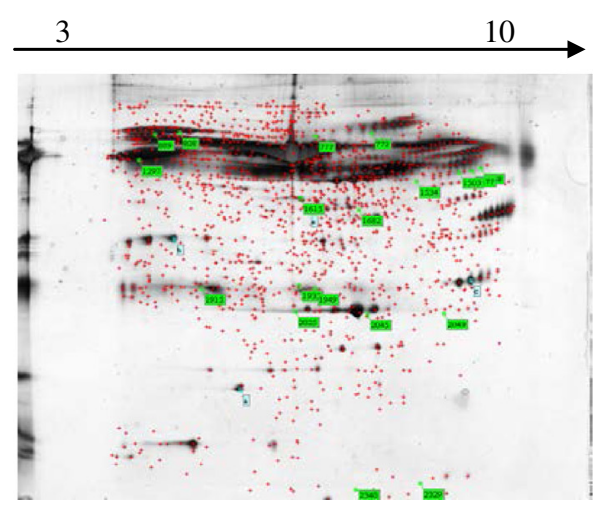

B

Fig. 1 Representative image of 2-DE gel by silver stained. Note: Identified spots of differentially expression proteins are indicated by green blank with spot number. $\mathbf{a}$ is from sick cows and (b) is from healthy cow 


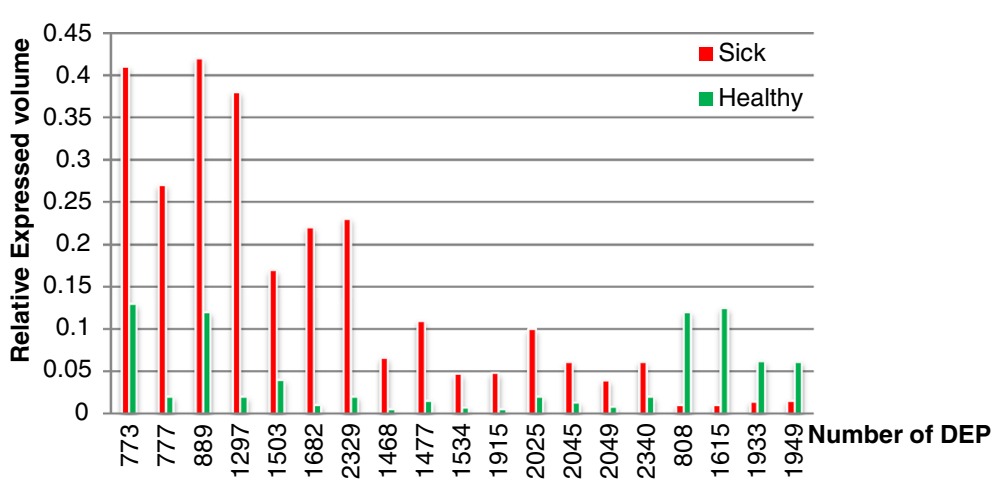

Fig. 2 The relative expressed volume of differentially expression proteins

were identified as the same protein of serum albumin, and spot2025 and spot2329 were the same protein of apolipoprotein A-IV (ApoA-IV) precursor. Finally, 4 kinds of proteins were down-regulated in expression in laminitis cows, which included ectoderm-neural cortex protein 1, glycerol-3-phosphate dehydrogenase 1-like protein, complement component 4 binding protein, and complement component $\mathrm{C} 9$ precursor, and 12 kinds of proteins were up-regulated in expression, which included 3-hydroxy-3-methylglutaryl-coenzyme A reductase (HMGCR), SPEG complex locus, serum albumin, complement component $\mathrm{C} 9$, haptoglobin, isocitrate dehydrogenase $1,60 \mathrm{~S}$ ribosomal protein L5, conglutinin, ApoA-IV, zinc finger protein 300like, transmembrane protein, and apolipoprotein A-I (apoA-I). The experimental molecular mass and isoelectric point of each protein was similar to the theoretical values.

Table 1 Identification of differentially expressed proteins in plasma in dairy cows with laminitis by MALDI TOF MS/MS

\begin{tabular}{|c|c|c|c|c|c|c|c|c|c|}
\hline \multicolumn{2}{|c|}{ NO. spot } & \multirow{2}{*}{$\begin{array}{l}\text { Change } \\
\text { UP }\end{array}$} & \multirow{2}{*}{$\begin{array}{l}\text { Protein name } \\
\begin{array}{l}\text { 3-hydroxy-3-methylglutaryl-Coenzyme A } \\
\text { reductase(HMGCR) }\end{array}\end{array}$} & \multirow{2}{*}{$\begin{array}{l}\text { NCBI } \\
\text { accession } \\
\text { gi|157785597 }\end{array}$} & \multirow{2}{*}{$\begin{array}{l}\text { pl; } \\
6.27 ;\end{array}$} & \multirow{2}{*}{$\begin{array}{l}\text { Mw } \\
99155\end{array}$} & \multirow{2}{*}{$\begin{array}{l}\text { Coverage } \\
33 \%\end{array}$} & \multirow{2}{*}{$\begin{array}{l}\text { Score } \\
184\end{array}$} & \multirow{2}{*}{$\begin{array}{l}\text { NO. of peptides } \\
\text { identified } \\
16\end{array}$} \\
\hline 1 & 773 & & & & & & & & \\
\hline 2 & 777 & UP & SPEG complex locus & gi|215599780 & 8.83 & 357571 & $6 \%$ & 73 & 15 \\
\hline 3 & 889 & UP & Serum albumin & gi|76445989 & 6.09 & 55487 & $18 \%$ & 78 & 6 \\
\hline 4 & 1297 & UP & Complement component C9; & gi|85718632 & 5.66 & 63327 & $20 \%$ & 108 & 9 \\
\hline 5 & 1468 & UP & serum albumin & gi|76445989 & 6.09 & 55487 & $18 \%$ & 73 & 5 \\
\hline 6 & 1477 & UP & serum albumin & gi|76445989 & 6.09 & 55487 & $27 \%$ & 78 & 8 \\
\hline 7 & 1503 & UP & Haptoglobin, HPT & gi|94966763 & 7.83 & 45629 & $47 \%$ & 136 & 9 \\
\hline 8 & 1534 & UP & Isocitrate Dehydrogenase 1, IDH1 & gi|89573995 & 6.12 & 41658 & $49 \%$ & 175 & 10 \\
\hline 9 & 1682 & UP & $60 S$ ribosomal protein L5, RPL5 & gi|78369655 & 9.73 & 34551 & $28 \%$ & 63 & 7 \\
\hline 10 & 1915 & UP & Conglutinin, CONG_BOVIN & gi|395268 & 5.82 & 38370 & $27 \%$ & 73 & 4 \\
\hline 11 & 2025 & UP & Apolipoprotein A-IV precursor & gi|296480272 & 5.30 & 42963 & $20 \%$ & 92 & 7 \\
\hline 12 & 2045 & UP & Zinc finger protein 300-like, ZNF300 & gi|297493133 & 8.66; & 27753 & $59 \%$ & 181 & 6 \\
\hline 13 & 2049 & UP & Transmembrane protein, TMP10 & gi59858239 & 6.85 & 15875 & $59 \%$ & 199 & 3 \\
\hline 14 & 2329 & UP & Apolipoprotein A-IV precursor, apoA-IV & gi|296480272 & 5.30 & 42963 & $55 \%$ & 174 & 5 \\
\hline 15 & 2340 & UP & Apolipoprotein A-I, apoA-I, apoA-I & gi|245563 & 5.57 & 28415 & $67 \%$ & 242 & 7 \\
\hline 16 & 808 & Down & Ectoderm-neural cortex protein 1, ENC1 & gi|118151210 & 6.40 & 67257 & $46 \%$ & 176 & 15 \\
\hline 17 & 1615 & Down & $\begin{array}{l}\text { Glycerol-3-phosphate dehydrogenase 1-like protein, } \\
\text { GPD1L }\end{array}$ & gi|154152135 & 6.13 & 38841 & $42 \%$ & 133 & 10 \\
\hline 18 & 1933 & Down & $\begin{array}{l}\text { complement component } 4 \text { binding protein, alpha } \\
\text { chain-like, C } 4 \mathrm{BP}\end{array}$ & gi|76677514 & 6.34 & 22393 & $42 \%$ & 123 & 6 \\
\hline 19 & 1949 & Down & complement component C9 precursor & gi|78369352 & 5.66 & 63327 & $18 \%$ & 101 & 7 \\
\hline
\end{tabular}


Function enrichment and GO analysis of DEP

To gain a better understanding of the 16 differentially expressed proteins identified in this study, further analysis was performed using bioinformatics. The identified proteins were categorized according to their function based on published literature and Uniprot database. These differential proteins were mainly classified by function into the following categories: carbohydrate metabolism, lipid metabolism, molecular transporter, immune regulation, inflammatory reaction, oxidative stress, and so on. By the GO analysis of AgBase, BPs of DEPs were mainly classified as biological processs (29\%), metabolic process (20\%), lipid metabolic process $(9 \%)$, regulation of biological process $(8 \%)$, transport of biomolecules $(7 \%)$, response to stress (5\%), and so on (Fig. 3a). MFs of DEPs were mainly classified as catalytic activity (27\%), binding (25\%),
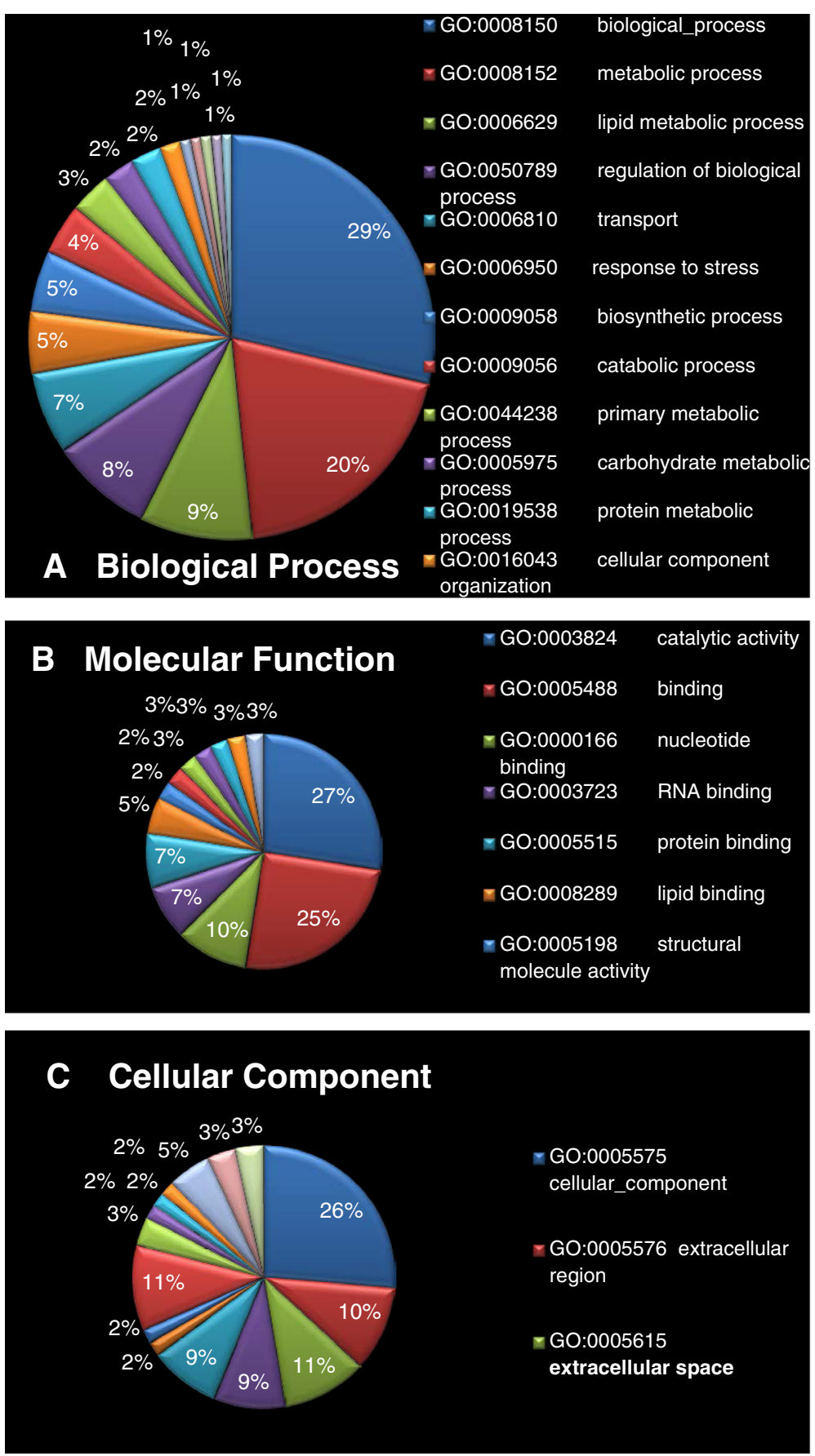

Fig. 3 The GO analysis of differently expressed protein. a is biological process; (b) is molecular function and (c) is cellular component 

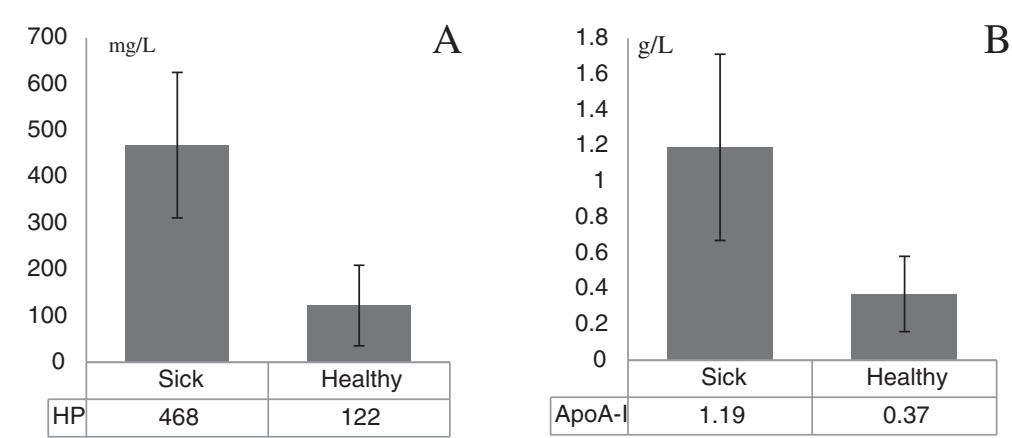

Fig. 4 Concentration of HP (a) and ApoA-I (b) of plasma by ELISA in the sick and healthy cows. Note. All data are expressed as mean $\pm \mathrm{SD}, p<0.05$

nucleotide binding (10\%), RNA binding (7\%), protein binding (7\%), lipid binding (5\%), and so on (Fig. 3b). CCs of DEPs were mainly classified as cellular component (26\%), cytoplasm (11\%), extracellular region (11\%), extracellular space (11\%), intracellular region (9\%), cell (9\%), and so on (Fig. 3c).

\section{Validation of 2-DE results}

To validate the accuracy of 2-DE results, haptoglobin and ApoA-I in plasma were successfully measured, respectively, by ELISA and immunoturbidimetric method. It indicated that the Mindray human test kits for ApoAI was also suitable for bovine. The results showed that haptoglobin $(P<0.01)$ and ApoA-I $(P<0.05)$ in the cows with laminitis were significantly higher than those in the healthy cows (Fig. 4). The differences in haptoglobin and ApoA-I concentrations were confirmed again. Although the fold changes were different from the results by 2$\mathrm{DE}$, the changing trend was consistent with2-DE, enhancing the possibility of the data of 2-DE being reliable.

\section{Analysis of antioxidant ability of plasma in dairy cows}

There were significant differences in the concentrations of T-AOC, MDA, and GSH-Px between sick and healthy groups $(P<0.01)$, but the concentration of SOD was not different between them (Table 2). The results indicated that the antioxidant ability of plasma decreased and the redox equilibrium was disturbed-caused by oxidative stress-in the sick cows. It was consistent with the proteomic results.

\section{Discussion}

Laminitis is a major cause of lameness in dairy cattle, which leads to serious economic loss for producers. But so far, the etiology and pathogenesis of laminitis in cow are not clear. The current situation gives us so many difficulties to prevent the disease. Comparative proteomics provide a novel pathway to resolve the question, Hannah [19] analyzed the proteomics of lamellar tissue of equine laminitis, and the results showed that COMP and keratins could serve as serum biomarkers for the developmental phase of laminitis. This study applied proteomics technology to compare the difference in the expression of plasma proteome between healthy and laminitis cows. A total of $16 \mathrm{DE}$ proteins were discovered of which 4 were down-regulated and 12 were up-regulated in expression. These DE proteins were involved in the pathways such as carbohydrate metabolism, lipids metabolism, molecular transport, immune regulation, inflammatory reaction, oxidative stress, and so on. The result has laid a good foundation to further understand the pathogenesis of laminitis in dairy cow.

\section{HMGCR - up-regulated expression}

HMGCR, transmembrane glycoprotein, is the ratelimiting enzyme in cholesterol biosynthesis [28]. The upregulated expression of HMGCR leads to increase in the biosynthesis volume of cholesterol. In hyperlipidemia and atherosclerosis, the HMGCR activity usually increases, so the competitive inhibitors of the reductase (e.g., statins) are used to lower HMGCR. In laminitis of cows, HMGCR was overexpressed, resulting in cholesterol accumulation in vascular inner wall, especially in the microcirculation blood capillary in hoof corium. The accumulation may cause blood hypoperfusion, even arteriosclerosis $[29,30]$, and then the occurrence of laminitis. The conclusion could be in accordance with the previous result [1]. So the lipid metabolic disturbance induced by the up-regulated expression of HMGR may be a pathway to cause laminitis in dairy cattle.

Table 2 Antioxidant ability of plasma in dairy cows

\begin{tabular}{llllll}
\hline Group & Number & $\begin{array}{l}\text { T-AOC } \\
\text { umol/L }\end{array}$ & SOD & MDA & GSH-Px \\
& & $5.82 \pm 0.2 \mathrm{a}$ & $58 \pm 7.2 \mathrm{a}$ & $3.4 \pm 0.5 \mathrm{a}$ & $27 \pm 3.4 \mathrm{a}$ \\
Sick & 36 & $7.2 \pm 1.45 \mathrm{~b}$ & $64 \pm 4.6 \mathrm{a}$ & $2.2 \pm 0.1 \mathrm{~b}$ & $41 \pm 4.2 \mathrm{~b}$ \\
Health & 15 & &
\end{tabular}

Different letters in the same column mean significant difference $(P<0.01)$ 


\section{ApoA-I and ApoA-IV—up-regulated expression}

Apolipoprotein is constituted of an important component of plasma lipoproteins, which have been found to bind lipopolysaccharide (LPS) in vitro and neutralize its toxic effects [31]. In vitro, apoA-IV plays antiinflammatory and antiatherogenic roles after the administration of LPS [32, 33]. Therefore, apolipoprotein may play a vital role in perpetuating the inflammatory response. In addition, ApoA-I participates in the reverse transport of cholesterol from tissues to the liver for excretion by promoting cholesterol efflux from tissues and by acting as a cofactor for the lecithin cholesterol acyltransferase. ApoA-IV is a major component of highdensity lipoprotein, which can promote cholesterol efflux to an equal extent from adipose cells [34]. In bovine, subacute ruminal acidosis was considered as the main cause of laminitis with the high level of LPS in blood [3, 12]. Therefore, ApoA-I and ApoA-IV were both up-regulated in expression to enhance the ability of the organism to neutralize the LPS toxicity; these proteins can transport cholesterol from tissue to liver for catabolism. In a research on horse with chronic laminitis, ApoA-IV was also found up-regulated in expression to play an anti-inflammatory role [35], which was in accordance with the findings of this study.

\section{Haptoglobin-up-regulated expression}

Haptoglobin is an important acute-phase protein, which can assess the innate immune system's systemic response to infection, inflammation, or trauma, including hemoglobin-binding capacity, in maintaining the iron homeostasis in cattle [36]. Haptoglobin also functions as a bacteriostatic agent, which increases rapidly during an infectious disease. At acute clinical mastitis in dairy cows, the haptoglobin concentration increases markedly both in blood and milk [37]. Haptoglobin concentrations increase to sixfold in dairy cows with infectious and metabolic diseases at slaughter compared to animals with minor lesions [38], In cattle, haptoglobin is effective in the diagnosis and prognosis of mastitis, enteritis, peritonitis, pneumonia, endocarditis, and endometritis [39]. Elevations in this protein have also been reported in cows with fatty liver syndrome, at parturition and during periods of starvation and transport stress, but not in laminitis. In this study, haptoglobin expression was found to be up-regulated in the case of laminitis, which prevents loss of iron and plays a vital role in anti-inflammatory reaction.

\section{Conglutinin-up-regulated expression}

Conglutinin is a 371-amino acid calcium-dependent serum lectin specific for $\mathrm{N}$-acetylglucosamine and plays an important role in defense mechanisms [40]. Conglutinin of cow is a member of the collectin protein family, which is an effector molecule in innate, non-adaptive immune defense against microorganism pathogens. Conglutinin binds to microbial surface wall and immune complexes through the complement component (C3bi), thereby impeding infectivity or mediating phagocytosis through specific receptors on phagocytes [41]. In the development of laminitis, conglutinin was up-regulated in expression, which indicated that the natural immune ability of cows may be improved.

\section{Conclusions}

The current study provides a novel report on plasma proteomic profiles of laminitis in dairy cows. The results highlight the differentially expressed proteins in blood plasma between healthy dairy cows and clinical laminitis cows, including 12 proteins up-regulated and 4 proteins down-regulated. Overall, these differential proteins were involved in the pathways including carbohydrate metabolism, lipid metabolism, molecular transport, immune regulation, inflammatory reaction, oxidative stress, and so on. The differentially expressed proteins were related to the occurrence and development of laminitis and the lipid metabolic disturbance may be a new pathway to cause laminitis in dairy cows. The results may provide some clues for further revealing the pathogenesis of laminitis and screening the early diagnostic proteins and therapeutic drug target.

\section{Abbreviations}

BP: Biological process; CAAS: Chinese academy of agricultural sciences; CC: Cellular component; CHAPS: 3-[(3-Cholamidopropyl)

dimethylammonio]-1-propanesulfonate; DEP: Differentially expressed proteins; DTT: Dithiothreitol; EDTA-K2: Dipotassium ethylene diamine tetra -acetate; ELISA: Enzyme-linked immunosorbent assay; GO: Gene ontology; GSH-Px: Glutathione peroxidase; IAA: lodoacetamide; IEF: Isoelectric Focusing; IPG: Immobilized pH gradient; MALDI-TOF MS: Matrix-assisted laser desorption/ionization time-of-flight mass spectrometry;

McAb: Monoclonal antibody; MDA: Malonaldehyde; MF: Molecular function; PBST: Phosphate buffer solution and Tween-20; PMF: Peptide mass fingerprinting; SOD: Super oxygen dehydrogenases; T-AOC: Total antioxidative capacity; 2-D:

Two-dimensional gel; 2-DE: Two-dimensional gel electrophoresis.

\section{Competing interests}

The authors declare that they have no competing interest.

\section{Authors' contributions}

ZTY and ZQY conceived and designed the study, and critically revised the manuscript. SWD, SDZ, and DSW performed the experiments and analyzed the results, and SWD drafted the manuscript. HW and XFS participated in ELISA and manuscript revision. PY helped in the 2-DE experiment. All authors read and approved the final manuscript.

\section{Acknowledgments}

The authors would like to thank Doctor Fuqiang Wang and Shiyang Xu of Nanjing medical University for the MS technical support. We are grateful to Doctor Qinzhe and Doctor Ali for his helpful scientific suggestion. This work was financially supported by the National Science Research Fund of China (No. 31302156), Chinese Central Public Interest Scientific Institution Basal Research Fund (No. 1610322010004), and the 12th five-year plan of Chinese national science and technology support (No. 2012BAD12B03). 


\section{Author details}

${ }^{1}$ Key Laboratory of Veterinary Pharmaceutical Development of Ministry of Agriculture/ Engineering \& Technology Research Center of Traditional Chinese Veterinary Medicine of Gansu Province/Lanzhou Institute of Husbandry and Pharmaceutical Sciences of Chinese Academy of Agricultural Sciences, Lanzhou 730050, People's Republic of China. ${ }^{2}$ Key Laboratory of Yak Breeding Engineering, Lanzhou 730050, People's Republic of China.

Received: 14 February 2015 Accepted: 8 July 2015

Published online: 23 July 2015

\section{References}

1. Boosman R, Nemeth F, Gruys E. Bovine laminitis: clinical aspects, pathology and pathogenesis with reference to acute equine laminitis. Vet $Q$. 1991;13(3):163-71.

2. Vermunt JJ. One step closer to unravelling the pathophysiology of claw horn disruption: for the sake of the cows' welfare. Vet J. 2007;174(2):219-20.

3. Mgasa MN. Bovine pododermatitis aseptica diffusa (laminitis) aetiology, pathogenesis, treatment and control. Vet Res Commun. 1987;11(3):235-41.

4. Svensson C, Bergsten C. Laminitis in young dairy calves fed a high starch diet and with a history of bovine viral diarrhoea virus infection. Vet Rec. 1997;140(22):574-7.

5. Sanders AH, Shearer JK, De Vries A. Seasonal incidence of lameness and risk factors associated with thin soles, white line disease, ulcers, and sole punctures in dairy cattle. J Dairy Sci. 2009:92(7):3165-74.

6. Danscher AM, Toelboell TH, Wattle O. Biomechanics and histology of bovine claw suspensory tissue in early acute laminitis. J Dairy Sci. 2010;93(1):53-62

7. Danscher AM, Enemark HL, Andersen PH, Aalbaek B, Nielsen OL. Polysynovitis after oligofructose overload in dairy cattle. J Comp Pathol. 2010;142(2-3):129-38.

8. Al-Qudah KM, Ismail ZB. The relationship between serum biotin and oxidant/ antioxidant activities in bovine lameness. Res Vet Sci. 2012;92(1):138-41.

9. Belge F, Bildik A, Belge A, Kilicalp D, Atasoy N. Possible association between chronic laminitis and some biochemical parameters in dairy cattle. Aust Vet J. 2004:82(9):556-7.

10. Bergsten C. Causes, risk factors, and prevention of laminitis and related claw lesions. Acta Vet Scand Suppl. 2003;98:157-66.

11. Kleen $J$ L, Hooijer GA, Rehage J, Noordhuizen JP. Subacute ruminal acidosis (SARA): a review. J Vet Med A Physiol Pathol Clin Med. 2003;50(8):406-14.

12. Enemark JM. The monitoring, prevention and treatment of sub-acute ruminal acidosis (SARA): a review. Vet J. 2008;176(1):32-43.

13. Harris P. Laminitis after 2000 years: adding bricks to our wall of knowledge. Vet J. 2012;191(3):273-4.

14. Talamo F, D'Ambrosio C, Arena S, Del VP, Ledda L, Zehender G, et al. Proteins from bovine tissues and biological fluids: defining a reference electrophoresis map for liver, kidney, muscle, plasma and red blood cells. Proteomics. 2003;3(4):440-60.

15. Eckersall PD, de Almeida AM, Miller I. Proteomics, a new tool for farm animal science. J Proteomics. 2012;75(14):4187-9.

16. Turk R, Piras C, Kovacic M, Samardzija M, Ahmed H, De Canio M, et al. Proteomics of inflammatory and oxidative stress response in cows with subclinical and clinical mastitis. J Proteomics. 2012;75(14):4412-28.

17. Piras C, Soggiu A, Bonizzi L, Greco V, Ricchi M, Arrigoni N, et al. Identification of immunoreactive proteins of Mycobacterium avium subsp. paratuberculosis. Proteomics. 2015:15(4):813-23.

18. Mankowski JL, Graham DR. Potential proteomic-based strategies for understanding laminitis: predictions and pathogenesis. J Equine Vet Sci. 2008;28(8):484-7.

19. Galantino-Homer H, Galantino-Homer H, Carter R, Linardi R, Megee $\mathrm{S}$, Engiles J, et al. The big picture: using quantitative proteomics to investigate laminitis pathophysiology. J Equine Vet Sci. 2011;31:562-3.

20. Galbraith H, Flannigan S, Swan L, Cash P. Proteomic evaluation of tissues at functionally important sites in the Bovine Claw. Cattle Practice. 2006;14:127-37.

21. Tolboll TH, Danscher AM, Andersen PH, Codrea MC, Bendixen E. Proteomics: a new tool in bovine claw disease research. Vet J. 2012;193(3):694-700.

22. Wagner IP, Rees CA, Dunstan RW, Credille KM, Hood DM. Evaluation of systemic immunologic hyperreactivity after intradermal testing in horses with chronic laminitis. Am J Vet Res. 2003;64(3):279-83.
23. Nordlund KV, Cook NB, Oetzel GR. Investigation strategies for laminitis problem herds. J Dairy Sci. 2004;87(Supplement):E27-35.

24. Wu J, Wang F, Gong Y, Li D, Sha J, Huang X, et al. Proteomic analysis of changes induced by nonylphenol in Sprague-Dawley rat Sertoli cells. Chem Res Toxicol. 2009;22(4):668-75.

25. Shevchenko A, Wilm M, Vorm O, Mann M. Mass spectrometric sequencing of proteins silver-stained polyacrylamide gels. Anal Chem. 1996;68(5):850-8.

26. Hajduch M, Casteel JE, Hurrelmeyer KE, Song Z, Agrawal GK, Thelen JJ. Proteomic analysis of seed filling in Brassica napus. Developmenta characterization of metabolic isozymes using high-resolution twodimensional gel electrophoresis. Plant Physiol. 2006;141(1):32-46.

27. Ruepp A, Waegele B, Lechner M, Brauner B, Dunger-Kaltenbach I, Fobo G, et al. CORUM: the comprehensive resource of mammalian protein complexes-2009. Nucleic Acids Res. 2010;38(Database issue):D497-501.

28. Elsik CG, Tellam RL, Worley KC, Gibbs RA, Muzny DM, Weinstock GM, et al. The genome sequence of taurine cattle: a window to ruminant biology and evolution. Science. 2009:324(5926):522-8.

29. Singh SS, Murray RD, Ward WR. Histopathological and morphometric studies on the hooves of dairy and beef cattle in relation to overgrown sole and laminitis. J Comp Pathol. 1992;107(3):319-28.

30. Boosman R, Nemeth F, Gruys E, Klarenbeek A. Arteriographical and pathological changes in chronic laminitis in dairy cattle. Vet $\mathrm{Q}$. 1989;11(3):144-55

31. Read TE, Harris HW, Grunfeld C, Feingold KR, Kane JP, Rapp JH. The protective effect of serum lipoproteins against bacterial lipopolysaccharide. Eur Heart J. 1993:14(Suppl K):125-9.

32. Spaulding HL, Saijo F, Turnage RH, Alexander JS, Aw TY, Kalogeris TJ. Apolipoprotein A-IV attenuates oxidant-induced apoptosis in mitotic competent, undifferentiated cells by modulating intracellular glutathione redox balance. Am J Physiol Cell Physiol. 2006;290(1):C95-C103.

33. Recalde D, Ostos MA, Badell E, Garcia-Otin AL, Pidoux J, Castro G, et al. Human apolipoprotein A-IV reduces secretion of proinflammatory cytokines and atherosclerotic effects of a chronic infection mimicked by lipopolysaccharide. Arterioscler Thromb Vasc Biol. 2004;24(4):756-61.

34. Duverger N, Murry-Brelier A, Latta M, Reboul S, Castro G, Mayaux JF, et al. Functional characterization of human recombinant apolipoprotein AIV produced in Escherichia coli. Eur J Biochem. 1991:201(2):373-83.

35. Steelman SM, Chowdhary BP. Plasma proteomics shows an elevation of the anti-inflammatory protein APOA-IV in chronic equine laminitis. BMC Vet Res. 2012;8(1):179.

36. Bowman BH. Haptoglobin. Hepatic plasma proteins. San Diego: Academic; 1993.

37. Cooray R, Waller KP, Venge P. Haptoglobin comprises about $10 \%$ of granule protein extracted from bovine granulocytes isolated from healthy cattle. Vet Immunol Immunopathol. 2007;119(3-4):310-5.

38. Hirvonen J, Hietakorpi S, Saloniemi H. Acute phase response in emergency slaughtered dairy cows. Meat Sci. 1997;46(3):249-57.

39. Eckersall PD, Bell R. Acute phase proteins: biomarkers of infection and inflammation in veterinary medicine. Vet J. 2010;185(1):23-7.

40. Zimin AV, Delcher AL, Florea L, Kelley DR, Schatz MC, Puiu D, et al. A whole-genome assembly of the domestic cow, Bos taurus. Genome Biol. 2009;10(4):R42.

41. Laursen SB, Thiel S, Teisner B, Holmskov U, Wang Y, Sim RB, et al. Bovine conglutinin binds to an oligosaccharide determinant presented by $\mathrm{iC} 3 \mathrm{~b}$, but not by C3, C3b or C3c. Immunology. 1994;81(4):648-54.

\section{Submit your next manuscript to BioMed Central and take full advantage of:}

- Convenient online submission

- Thorough peer review

- No space constraints or color figure charges

- Immediate publication on acceptance

- Inclusion in PubMed, CAS, Scopus and Google Scholar

- Research which is freely available for redistribution 